\title{
FINE GRAIN STRUCTURE AS PALLIATIVES FOR FRETTING WEAR OF INCONEL 718 ALLOY AT VARIOUS TEMPERATURES
}

\author{
Auezhan Amanov ${ }^{1}$, Young-Sik Pyun ${ }^{1}$, Wang Qingyuan ${ }^{2}$, Muhammad Kashif Khan ${ }^{3}$ \\ ${ }^{1}$ Department of Mechanical Engineering, Sun Moon University, Asan 336-708, South Korea \\ ${ }^{2}$ Department of Civil Engineering and Mechanics, Sichuan University, Chengdu 610065, China \\ ${ }^{3}$ Department of Mechanics and Engineering Science, Sichuan University, Chengdu 610065, \\ China
}

Keywords: Inconel 718 Alloy, Microstructure, Fretting wear, Grain size

\begin{abstract}
In this study, the effectiveness of an ultrasonic nanocrystalline surface modification (UNSM) technique on the fretting wear and frictional properties of a nickel-based super alloy Inconel 718, which was developed for use in rotating part in aerospace and gas turbine applications, was investigated at various temperatures. The results showed that the UNSM-treated specimens reduced the friction coefficient and palliated the fretting wear compared to the untreated conventional specimens, which may be attributed to the fine grain structure, decrease in surface roughness and increase in surface hardness. Also, it was found that the UNSM technique had no effect on the chemical composition of Inconel 718 alloy.
\end{abstract}

\section{Introduction}

Inconel 718 is a nickel-based superalloy that is extensively used in a broad range of applications such as turbine blades, power generation, petroleum and nuclear reactor technology due to its good mechanical properties at intermediate and high temperatures [1]. Today, these materials are being used in gas turbines, the aviation industry, nuclear reactors, and many applications where high temperatures are used [2]. However, in contrast to its wide range of usage, high plasticity and good corrosion resistance, poor wear resistance of Inconel 718 alloy limits its usage in some applications. Although it has good corrosion and oxidation resistance, it is subjected to high wear levels where materials are slide one part to another and wear of alloy can cause the failure [3]. Fretting is a progressively damage of materials, which occurs inevitably when two contacting surfaces exhibit small amplitude oscillatory motion. A combination of this motion and pressure exerted between interacting surfaces generates significant superficial stress concentration which can result in material removal and consequently can degrade fatigue lifetime of aerospace components which may lead to catastrophic failure or loss of functionality [4]. An ultrasonic nanocrystalline surface modification (UNSM) is a newly developed surface modification technique. It has been demonstrated among the different surface modification techniques that this technique is an effective and economical method to produce a nanostructured materials by refining the coarse grains to nanometer scale without changing the chemical composition in metallic materials which render the high strength and high ductility. It does not only improve the mechanical and tribological properties of various metallic materials by severe plastic deformation (SPD) method, but also produces a corrugated structure and number of desired micro-dimples on the treated surface. More details of UNSM technique including the effectiveness on the mechanical and tribological properties of metallic materials can be found in our previous study [5]. The objective of this present study is to gain a better understanding of the 
UNSM technique on microstructural evolution and fretting wear properties in Inconel 718 alloy at different fretting temperatures.

\section{Experimental Procedure}

In this study, a series of Inconel 718 alloy disk specimens, with dimensions of $24 \mathrm{~mm}$ in diameter and $7.9 \mathrm{~mm}$ in thickness, were employed. Some of the specimens were treated by the UNSM treatment under strictly controlled parameters as shown in Table I. The comparison of a typical corresponding element distribution maps and chemical composition of the untreated and UNSM-treated Inconel 718 alloy specimens employed in this study is shown in Figure 1. It can be seen that the UNSM technique had no effect on the chemical composition of Inconel 718 alloy. Prior to UNSM treatment, the specimens were cleaned in acetone $\left(\mathrm{CH}_{3}\right)_{2} \mathrm{CO}$ and petroleum benzene $\left(\mathrm{C}_{6} \mathrm{H}_{6}\right)$ mixture (ratio 1:1) for $10 \mathrm{~min}$ each using an ultrasonic bath to remove the impurities and particles from the surface.
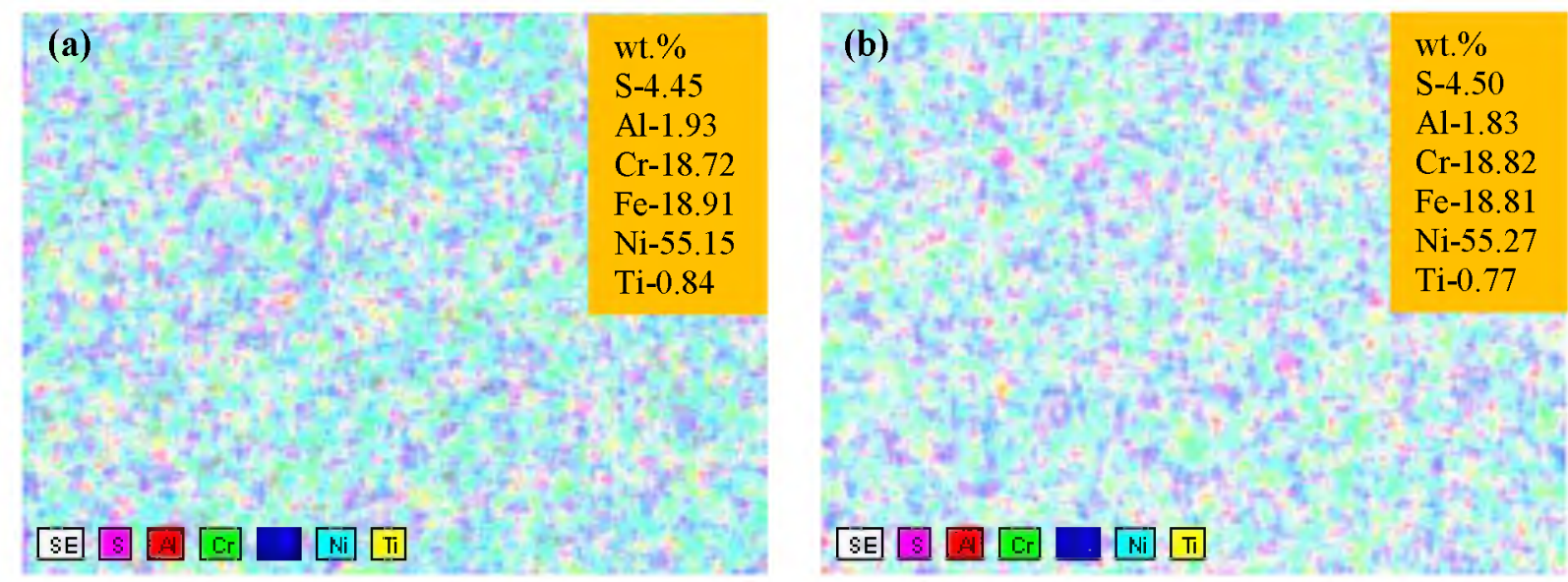

Figure 1. Chemical elements mapping of the untreated (a) and UNSM-treated (b) Inconel 718 alloy specimens.

Table I. UNSM Treatment Parameters

\begin{tabular}{|c|c|c|c|c|c|c|}
\hline $\begin{array}{c}\text { Frequency, } \\
\mathrm{kHz}\end{array}$ & $\begin{array}{c}\text { Amplitude, } \\
\mu \mathrm{m}\end{array}$ & $\begin{array}{c}\text { Horn speed, } \\
\mathrm{mm} / \mathrm{min}\end{array}$ & $\begin{array}{c}\text { Impact load, } \\
\mathrm{N}\end{array}$ & $\begin{array}{c}\text { Interval, } \\
\mathrm{mm}\end{array}$ & $\begin{array}{c}\text { Ball } \\
\text { diameter, } \\
\mathrm{mm}\end{array}$ & $\begin{array}{c}\text { Ball } \\
\text { material }\end{array}$ \\
\hline 20 & 30 & 3000 & 80 & 0.04 & 2.38 & $\mathrm{WC}$ \\
\hline
\end{tabular}

The frictional and fretting wear properties of the untreated and UNSM-treated specimens were investigated using a schwingung reibung verschleiss (SRV4, Germany) ball-on-disk tribometer at a load of $50 \mathrm{~N}$, frequency of $50 \mathrm{~Hz}$, temperatures of $25^{\circ} \mathrm{C}, 100{ }^{\circ} \mathrm{C}$ and $200{ }^{\circ} \mathrm{C}$ with a stroke of $100 \mu \mathrm{m}$ for $30 \mathrm{~min}$ under dry conditions. A bearing steel ball with a diameter of $10 \mathrm{~mm}$ was used as a counter surface specimen, which was selected because of its various applications. Each specimen was tested at least three times due to the data scattering. The hardness measurement of the specimens was performed using the Vickers hardness tester (Akashi Corp. AAV-4M, Japan) with a diamond pyramid Vickers indenter at a load of $10 \mathrm{~N}(1 \mathrm{kgf})$ and constant indenter dwell time of $30 \mathrm{~s}$. All indentation tests were carried out under ambient laboratory conditions.

The surface morphology and fretting wear tracks investigated using a field emission scanning electron microscope (FE-SEM; SUPRA40, Zeiss, Germany. The chemical composition of the 
specimens was investigated using an energy dispersive X-ray spectroscope (EDS) system installed in a FE-SEM. X-ray diffraction (XRD) was carried out using a Bruker D8-Discover Advance and X3000 (X stress 3000) X-ray diffractometer with $\mathrm{Cu} \mathrm{K \alpha}$ radiation in the range of $2 \theta=50-100^{\circ}$ with a step of $0.5^{\circ}$ at a voltage of $35 \mathrm{kV}$ and current of $40 \mathrm{~mA}$ to reveal information about the microstructure and phase identification of the specimens at the top surface. The average surface roughness of the specimens and cross-sectional surface profiles of the fretting wear scars were obtained using a surface profilometer (Surfcom 1500 SD3, Accretech, Japan). The cross-sectional profiles of the wear tracks were measured at three different points to quantify the wear volume. The specific wear rate and the corresponding standard deviation were quantified as the ratio of wear volume loss over the normal load multiplied by total reciprocating sliding distance.

\section{Results and Discussion}

\section{$\underline{\text { Microstructure }}$}

Figure 2 shows the comparison of surface morphology for the untreated and UNSM-treated specimens. It is evident that significant changes in microstructure and reduction in surface roughness on the surface of the UNSM-treated specimens were observed. The average surface roughness $\left(R_{a}\right)$ of the specimens was found to be $0.12 \mu \mathrm{m}$ and $0.09 \mu \mathrm{m}$ for the untreated and UNSM-treated specimens, respectively. The surface hardness of the untreated and UNSMtreated specimens was found to be about $361 \mathrm{HV}$ and $424 \mathrm{HV}$, respectively. Figure 3 presents the XRD patterns of the untreated and UNSM-treated specimens. It is obvious from the XRD pattern of the UNSM-treated specimen that the full width at half maximum (FWHM) of diffraction peak broadened and the diffraction intensity peaks decreased compared to that of the untreated specimen, which means that the grains of the UNSM-treated specimen were refined. The FWHM results of the highest peak calculated by pseudo-Voigt function were found to be 0.48 and 0.59 for the untreated and UNSM-treated specimens, respectively. It has been well known that the FWHM broadening occurs as a result of small grain size [6].
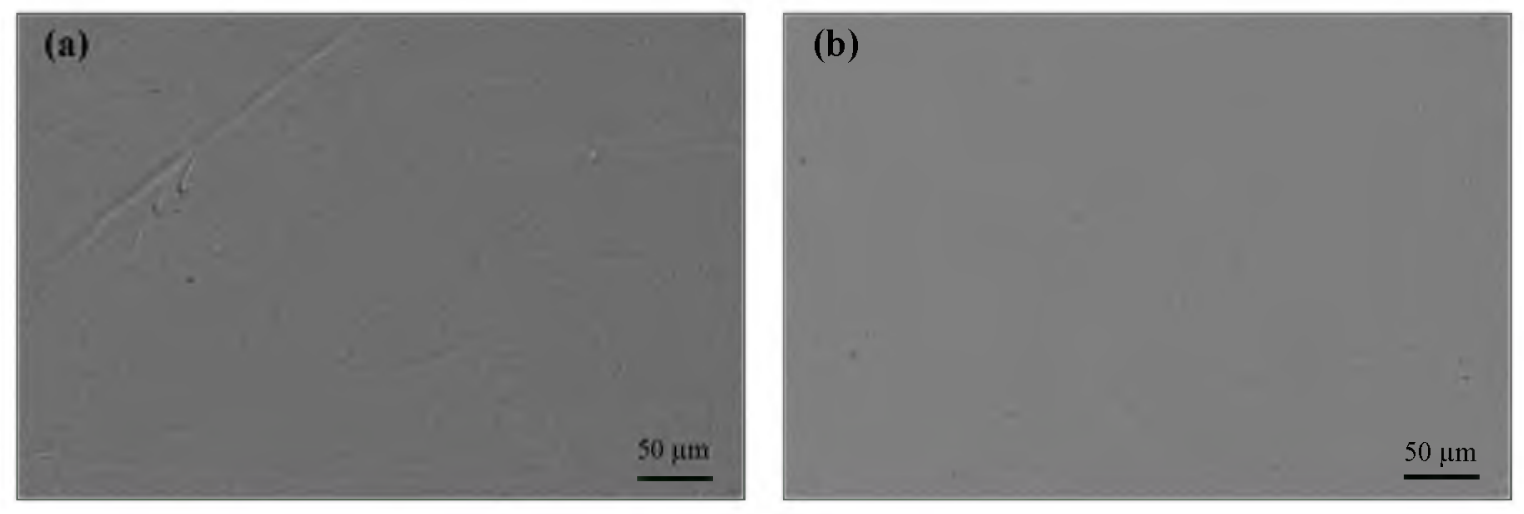

Figure 2. Surface morphology of the untreated (a) and UNSMtreated (b) Inconel 718 alloy specimens. 


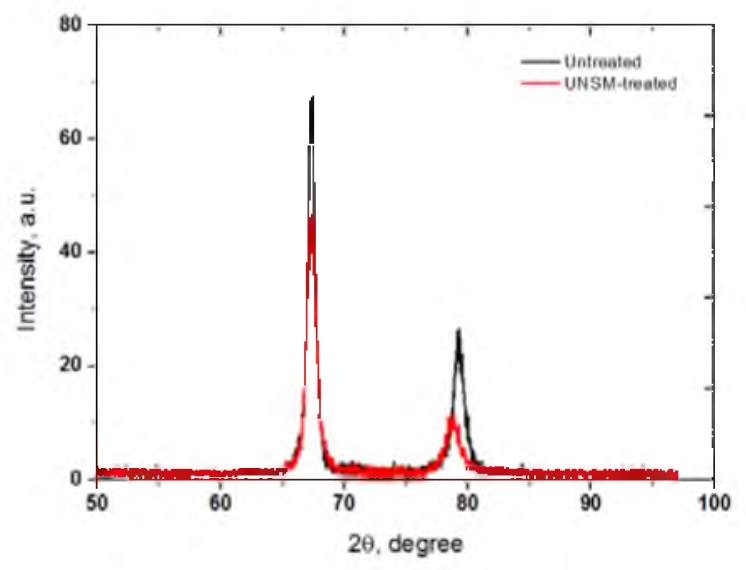

Figure 3. XRD patterns of the untreated and UNSM-treated Inconel 718 alloy specimens

The calculation results showed that the average grain size in the topmost surface layer of the untreated and UNSM-treated specimens were about $48 \mu \mathrm{m}$ and $94 \mathrm{~nm}$, respectively. It has also been reported in our previous study that the average grain size of the untreated and UNSMtreated AZ91D magnesium alloy was about $41.62 \mu \mathrm{m}$ and $39 \mathrm{~nm}$, respectively [7]. It is also evident from Figure 4 that the grain size of the UNSM-treated specimen increased gradually from nanometer to micrometer scale with increasing depth from the top surface, while the grain size of the untreated specimen did not change significantly.

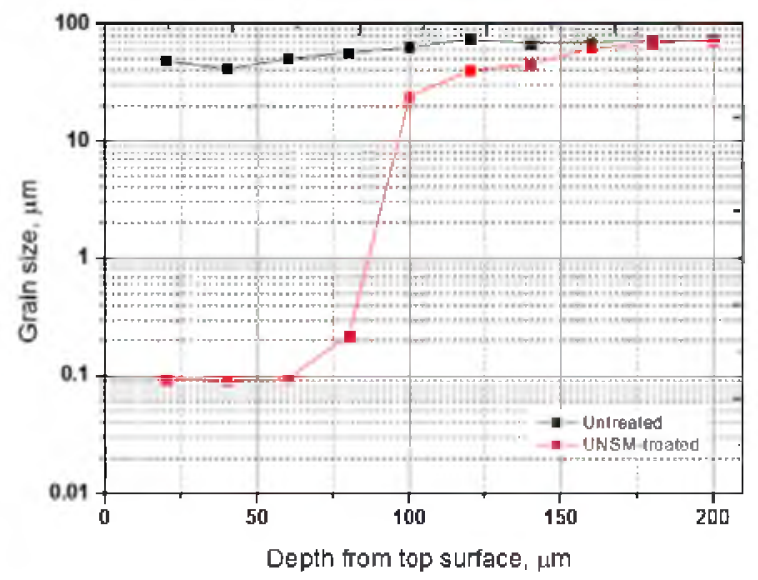

Figure 4. Variation in the average grain size with respect to depth for the untreated and UNSM-treated Inconel 718 alloy specimens.

\section{$\underline{\text { Friction coefficient and fretting wear scar }}$}

Figure 5 shows the variation in friction coefficient of the untreated and UNSM-treated specimens as a function of fretting time at a normal load of $50 \mathrm{~N}$ at temperatures of $25{ }^{\circ} \mathrm{C}, 100{ }^{0} \mathrm{C}$ and $200{ }^{\circ} \mathrm{C}$. It can be seen that the UNSM-treated specimens exhibited decrease in friction coefficient compared to those of the untreated specimens at all the temperatures. It was found that the friction coefficient increased with increasing the temperature for the untreated and UNSMtreated specimens. 
Figure 6 shows the FE-SEM images of fretting wear scars generated at temperatures of $25{ }^{0} \mathrm{C}$, $100{ }^{\circ} \mathrm{C}$ and $200{ }^{\circ} \mathrm{C}$ at a normal load of $50 \mathrm{~N}$. It can be see that the fretting wear scars of the UNSM-treated specimens were smaller than those of the untreated specimens. A comparison of wear rate of the specimens, which was quantified according to the cross-sectional fretting wear scar profiles, is shown in Figure 7. It was obvious from Figure 6 that the UNSM-treated specimens showed an increase in resistance to fretting wear compared to those of the untreated specimens at temperatures of $25{ }^{\circ} \mathrm{C}, 100{ }^{\circ} \mathrm{C}$ and $200{ }^{\circ} \mathrm{C}$. These improvements may be attributed to the decrease in surface roughness and increase in surface hardness.
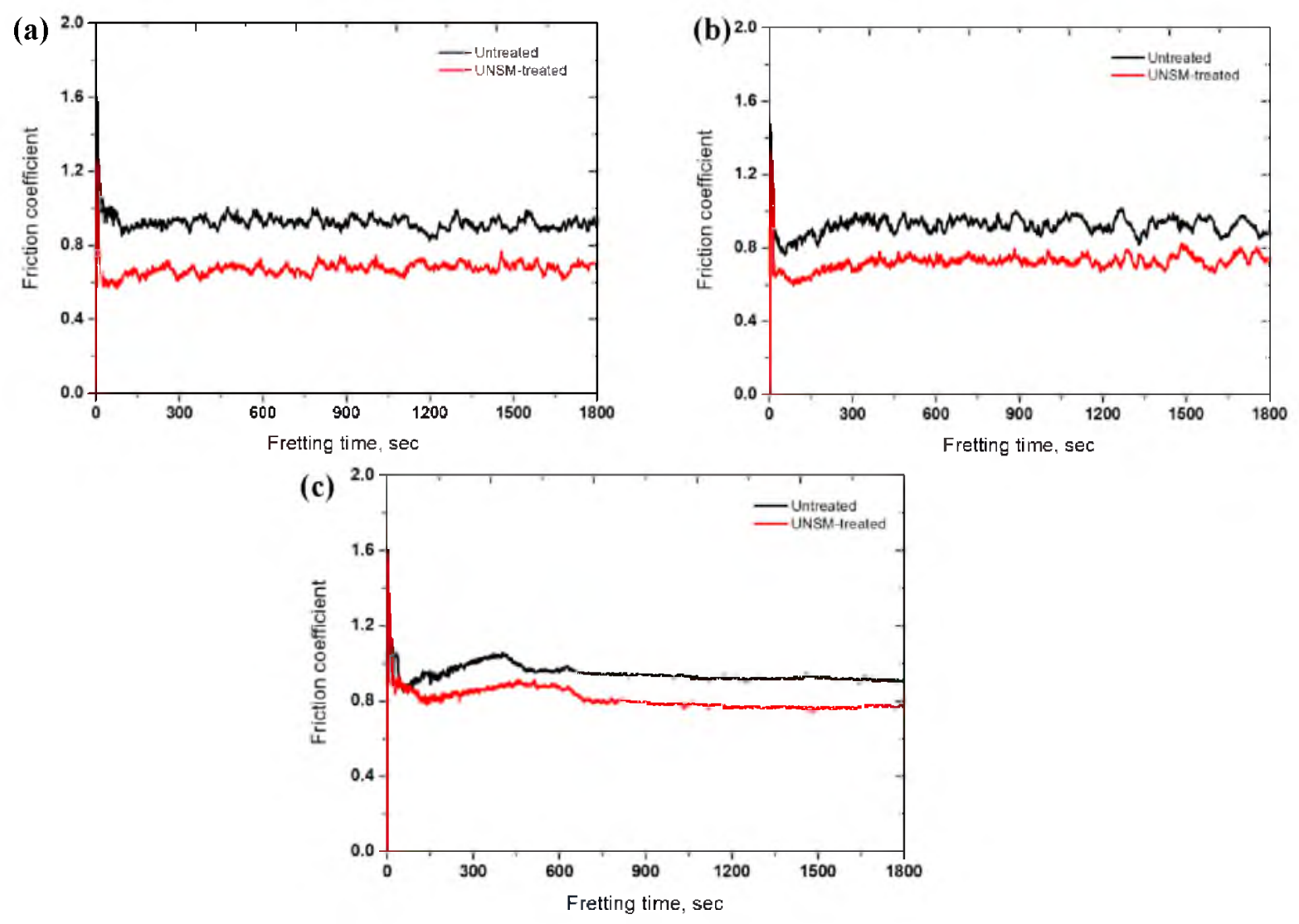

Figure 5. Variation in friction coefficient of the untreated and UNSM-treated specimens as a function of fretting time at a normal load of $50 \mathrm{~N}$, temperatures of $25{ }^{\circ} \mathrm{C}$ (a), $100{ }^{0} \mathrm{C}$ (b) and $200{ }^{\circ} \mathrm{C}(\mathrm{c})$.
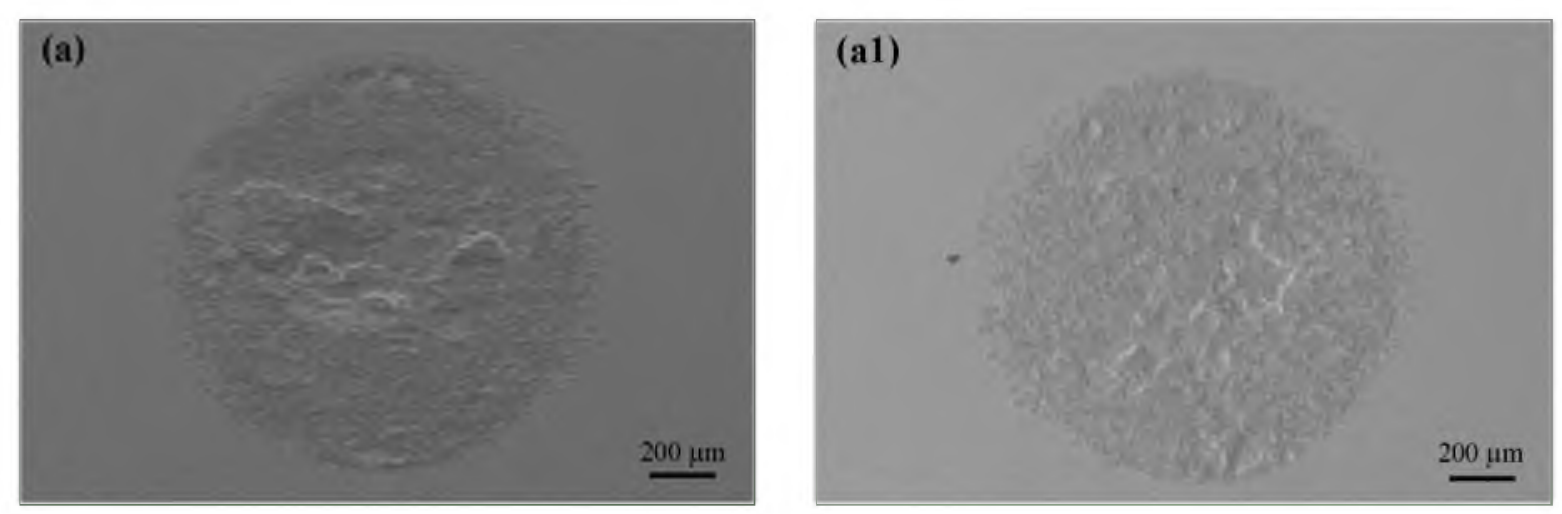

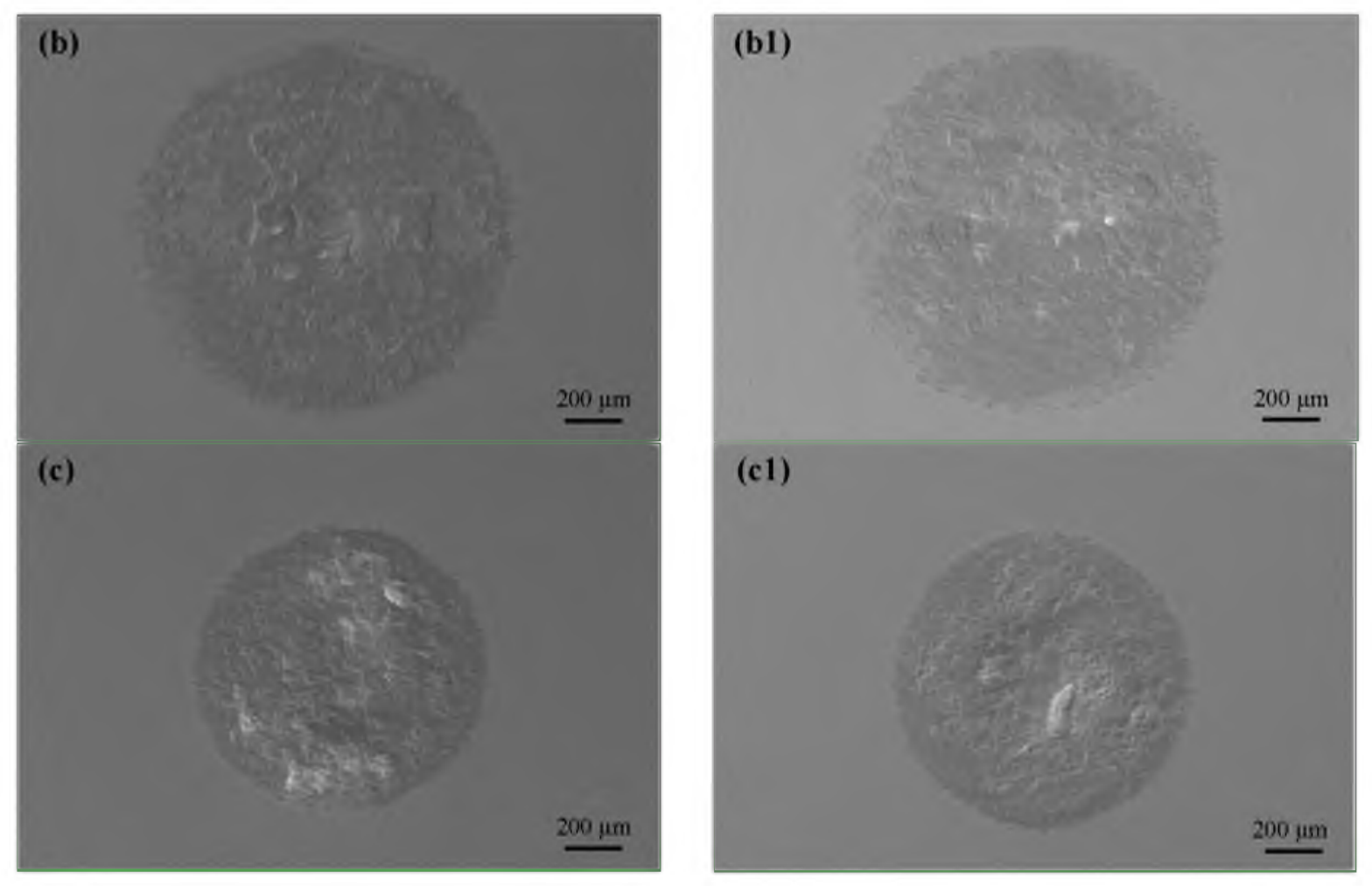

Figure 6. FE-SEM images of fretting wear scars generated at a normal load of $50 \mathrm{~N}$, temperatures of $25{ }^{\circ} \mathrm{C}(\mathrm{a}), 100{ }^{\circ} \mathrm{C}$ (b) and $200{ }^{0} \mathrm{C}(\mathrm{c})$.

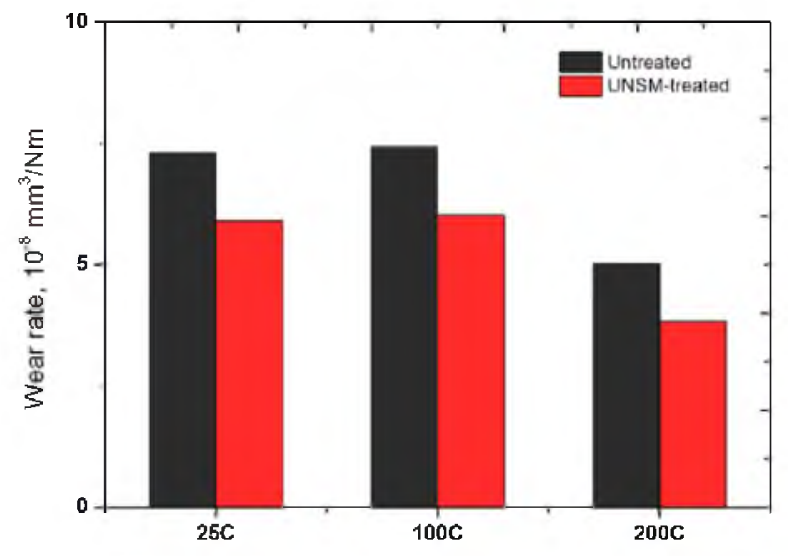

Figure 7. Comparison of wear rate for the untreated and UNSMtreated specimens at temperatures of $25{ }^{\circ} \mathrm{C}, 100{ }^{\circ} \mathrm{C}$ and $200{ }^{\circ} \mathrm{C}$.

Figure 8 shows the typical corresponding element distribution maps of the untreated specimen at a temperature of $25^{\circ} \mathrm{C}$. EDS mapping result revealed that after fretting wear test that the concentration of $\mathrm{Ni}$ and $\mathrm{Cr}$ elements is significantly decreased and $\mathrm{Fe}$ is significantly increased, while $\mathrm{S}, \mathrm{Al}$ and $\mathrm{Ti}$ have been changed inside the fretting wear scar. It is believed that the significant increase in Fe elements has been transferred from the counter surface bearing steel ball. 

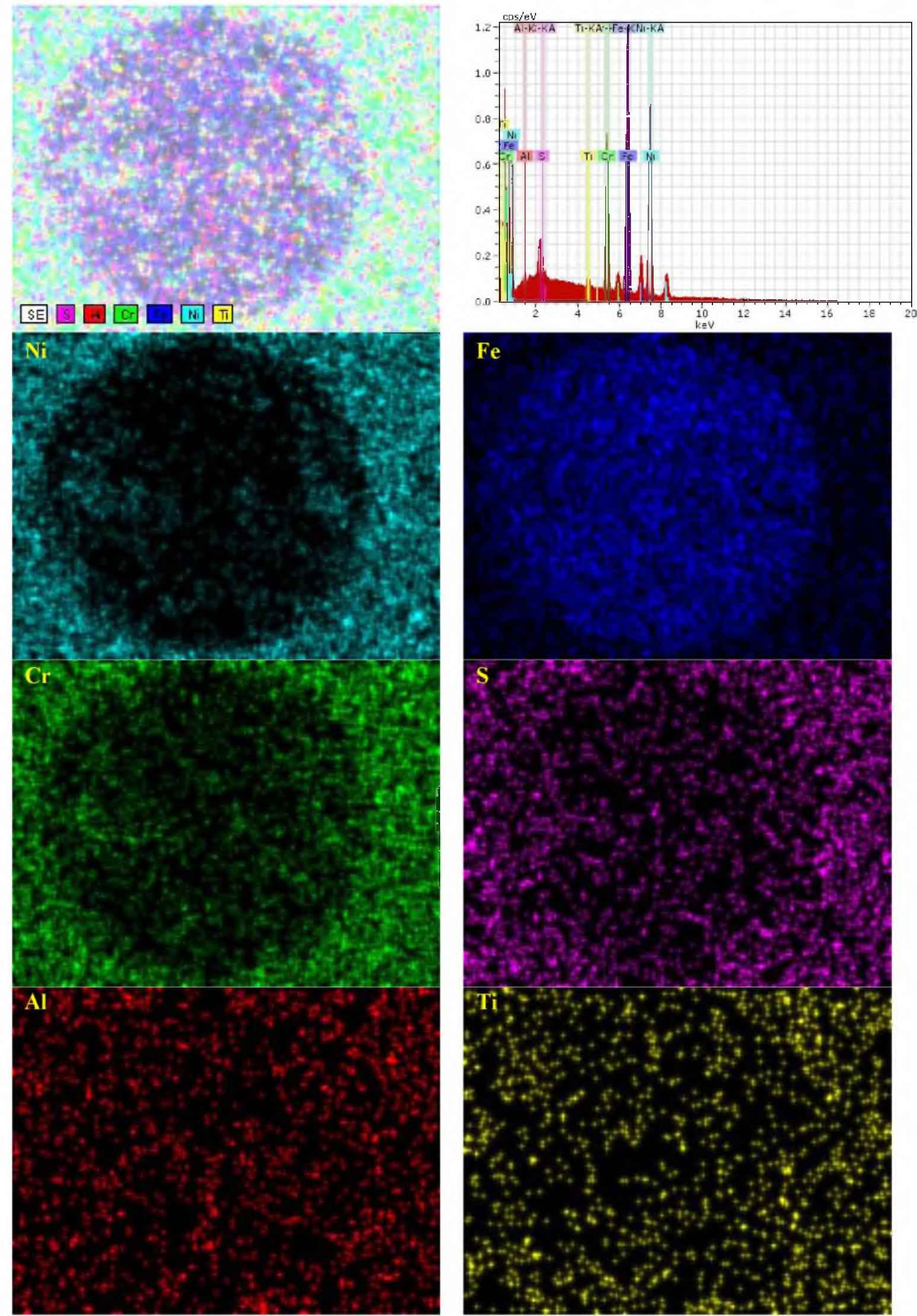

Figure 8. Typical corresponding element distribution maps of the untreated specimen at a temperature of $25{ }^{\circ} \mathrm{C}$. 


\section{Conclusions}

In this study, the effectiveness of the UNSM technique on the fretting wear and frictional properties of a nickel-based super alloy Inconel 718 alloy, which was developed for use in rotating part in aerospace and gas turbine applications, was investigated at various temperatures. From the experimental results, the following conclusions could be drawn:

- It was found that the UNSM technique may reduce the surface roughness and increase the surface hardness.

- The UNSM technique had no significant effect on the chemical composition of Inconel 718 alloy.

- The friction and wear behavior of Inconel 718 alloy was improved by the UNSM technique.

- The XRD results revealed that the grain size of Inconel 718 alloy was refined by the UNSM technique.

- It was evident according to the obtained experimental results that the UNSM technique is a sophisticated surface modification technique to improve the mechanical and tribological properties of Inconel 718 alloy.

- It is highly recommended to apply this technique to Inconel 718 alloy in order to further improve the mechanical and tribological properties with the aim of extending its applications in various industries.

\section{References}

1. A. Gill, A. Telang, S. R. Mannava, D. Qian, Y. S. Pyoun, H. Soyama, and V. K. Vasudevan, "Comparison of Mechanisms of Advanced Mechanical Surface Treatments in Nickel-based Superalloy," Materials Science \& Engineering A, 576 (2013), 346-355.

2. A. Bhatt, H. Attia, R. Vargas, and V. Thomson, "Wear Mechanisms of WC Coated and Uncoated Tools in Finish Turning of Inconel 718," Tribology International, 43(5-6) (2010), 1113-1121.

3. A. Houghton, R. Lewis, U. Olofsson, and J. Sundh, "Characterising and Reducing Seizure Wear of Inconel and Incoloy Superalloys in a Sliding Contact," Wear, 271(9-10) (2011), 1671-1680.

4. A. Amanov, T. Watabe, R. Tsuboi, and S. Sasaki, "Fretting Wear and Fracture Behaviors of Cr-doped and Non-doped DLC Films Deposited on Ti-6Al-4V Alloy by Unbalanced Magnetron Sputtering," Tribology International, 62, (2013), 49-57.

5. A. Amanov, Y.S. Pyoun, I.S. Cho, C.S. Lee, and I.G. Park, "Micro-dimpled Surface by Ultrasonic Nanocrystal Surface Modification and its Tribological Effects," Wear, 286-287 (2012), 136-144.

6. B.D. Cullity, S.R. Stock, "Elements of X-ray Diffraction," Upper Saddle River, New Jersey: Prentice Hall; 2001.

7. A. Amanov, O.V. Penkov, Y.S. Pyun, D.E. Kim, "Effects of ultrasonic nanocrystalline surface modification on the tribological properties of AZ91D magnesium alloy," Tribology International, 54, (2012), 106-113. 